\title{
Articulatory rehearsal and phonological storage in working memory
}

\author{
A. M. LONGONI \\ Università degli Studi di Roma "La Sapienza," Rome, Italy \\ J. T. E. RICHARDSON \\ Brunel University, Uxbridge, Middlesex, England \\ and \\ A. AIELLO \\ Università degli Studi di Roma "La Sapienza," Rome, Italy
}

\begin{abstract}
The theoretical distinction between an articulatory control process and a short-term phonological store was supported in five experiments on immediate serial recall. In Experiment 1, articulatory suppression during the presentation and recall of auditory material abolished the word length effect but not the phonemic similarity effect. In Experiment 2, the two latter effects were found to be independent with auditory presentation. In Experiment 3, the effects of irrelevant speech and word length were found to be independent with visual presentation. In Experiment 4, articulatory suppression during the presentation and recall of auditory material abolished the phonemic similarity effect with a slow presentation rate. Nevertheless, in Experiment 5, articulatory suppression with a conventional presentation rate did not reduce the effect of phonemic similarity, even when a 10-sec interval was interposed between presentation and recall. These results indicate that the encoding, maintenance, and retrieval of spoken material within the phonological store do not depend on a process of articulatory rehearsal.
\end{abstract}

Recent theoretical developments in the field of working memory have depended on the identification and investigation of converging operations that rule out competing hypotheses about different hypothetical components (Baddeley, 1986, p. 114; Hitch, 1980; cf. Garner, Hake, \& Eriksen, 1956). In immediate serial recall, performance is reliably affected by a number of properties of the stimulus items or of the procedure under which they are learned: (1) the degree of phonemic confusability among the items to be remembered (the phonemic similarity effect); (2) the articulatory duration of the items to be remembered (the word length effect); (3) the modality of presentation of the items to be remembered; (4) requiring the subjects to engage in the concurrent vocalization of irrelevant speech sounds (the effect of articulatory suppression); and (5) the concurrent presentation of irrelevant speech sounds that are to be ignored (the effect of unattended speech). The specific pattern of interrelation-

The authors' collaboration was made possible by travel grants under an agreement between the Royal Society and the Consiglio Nazionale della Ricerche. They are grateful to Jill Bayfield, Morag MacLean, and Johanne Reed for their assistance in running Experiment 4, to Marion Gallasch and Anna van Leemputten for their assistance in running Experiment 5, and to Nelson Cowan, Vernon Gregg, Dylan Jones, Bob Logie, Robert Proctor, Pierre Salamé, Arthur Samuel, and Norman Slamecka for their comments on earlier versions of this paper. Requests for reprints should be addressed to A. M. Longoni, Dipartimento di Psicologia, Università degli Studi di Roma "La Sapienza," Via degli Apuli 8, 00185 Roma, Italy. ships that has been observed among these various experimental effects has motivated a theoretical distinction between an articulatory control process and a short-term phonological store. The latter is supposed to hold a limited amount of material in a speech-like representation that is vulnerable to rapid decay unless it is refreshed through overt or covert articulatory rehearsal (see Baddeley, 1986, pp. 92-96; 1990, p. 72). Taken together, these components constitute a subsystem of working memory known as the "articulatory loop.",

This subsystem was initially postulated by Baddeley, Thomson, and Buchanan (1975), who demonstrated that performance in immediate serial recall varied inversely with the articulatory duration of the stimulus items, but that this word length effect was abolished by articulatory suppression during visual presentation. Previous experiments had found that under the latter conditions the phonemic similarity effect was also abolished (Murray, 1967; Peterson \& Johnson, 1971; see also Conrad, 1972; Richardson, Greaves, \& Smith, 1980). Baddeley et al. (1975) took these findings to mean that working memory employed a speech-based or articulatory form of encoding that functioned rather like a tape loop of limited duration (see also Baddeley, 1976, p. 178; 1979).

Nevertheless, the effects of articulatory suppression are somewhat more complicated under conditions of auditory presentation. In this case, articulatory suppression during the presentation phase alone gives rise to a slight reduction in the overall level of performance, but the phonemic 
similarity effect (Levy, 1971; Murray, 1968; Peterson \& Johnson, 1971) and the word length effect (Baddeley et al., 1975) are both preserved. However, this procedure leaves subjects free to engage in articulatory rehearsal during the test phase while they are recalling the first few items (Baddeley \& Lewis, 1984). Baddeley, Lewis, and Vallar (1984) found that articulatory suppression imposed during both presentation and recall abolished the word length effect but not the phonemic similarity effect. Morris (1984) tested patients with Alzheimer's disease and normal elderly control subjects, and obtained a similar pattern of findings merely as the result of articulatory suppression during presentation. He concluded that elderly subjects in general lacked the processing resources needed to make efficient use of articulatory rehearsal during the test phase. Finally, patients have been described with grossly impaired short-term memory who demonstrate effects of phonemic similarity in their recall performance but no effects of either articulatory suppression or word length (e.g., Vallar \& Baddeley, 1984; Vallar \& Cappa, 1987).

Such evidence tends to suggest that the word length effect and the phonemic similarity effect correspond to functionally distinct components of the articulatory loop. More specifically, it implies that the storage capability of the articulatory loop is based upon the use of an abstract phonological code that is neither articulatory in nature nor contingent upon the process of articulatory rehearsal. Baddeley et al. (1984) themselves concluded that the word length effect reflected the use of an articulatory control process, but that the phonemic similarity effect reflected the contribution of a short-term phonological store to which spoken material could gain direct access without the mediation of articulatory rehearsal (see also Baddeley, 1986, pp. 84-85). This store was thus conceptualized as a passive input register, rather than as a response buffer for verbal output of the sort envisaged in the original model of working memory (see Baddeley \& Hitch, 1974; cf. Hitch, 1980).

The purpose of the present investigation was to pursue the logic of converging operations in evaluating this account of the articulatory loop subsystem of working memory. We were interested in assessing the proposed functional distinction between a phonological store and a control process of articulatory rehearsal in several experiments that contrasted different operational indicators of the hypothetical components of the articulatory loop subsystem. In Experiments 1 and 2, the phonemic similarity effect was taken as an operational indicator of the use of the phonological store, whereas the effects of word length and of articulatory suppression were taken as operational indicators of the articulatory control process. In Experiment 3, the effect of word length was contrasted with the effect of unattended speech, taken as an alternative indicator of the phonological store. Finally, the impact of articulatory suppression upon the phonemic similarity effect was examined when the stimulus items were presented at a conventional rate or a relatively slow rate (Ex- periment 4) and when the test of serial recall was either immediate or delayed (Experiment 5).

\section{EXPERIMENT 1}

As mentioned above, the word length effect is assumed to result from the articulatory control process, whereas the phonemic similarity effect is assumed to result from the use of phonological storage. These assumptions entail that under conditions of silent learning, the articulatory duration and the phonemic confusability of the items to be remembered should exert additive and independent effects upon performance in a test of immediate serial recall. In other words, sequences of phonemically confusable items should be more difficult to recall than sequences of phonemically distinct items, regardless of how long they might take to articulate; conversely, sequences of long items should be more difficult to recall than sequences of short items, regardless of their phonemic confusability. If, however, the word length effect and the phonemic similarity effect are alternative indicators of a single hypothetical component, then these effects should interact with one another in a meaningful and predictable manner (cf. Garner et al., 1956). To be specific, the word length effect should be attenuated in the case of phonemically confusable sequences (or possibly even abolished altogether; cf. Salamé \& Baddeley, 1986), and the phonemic similarity effect should be attenuated in the case of sequences of longer stimulus items.

The investigation reported by Baddeley et al. (1984) did not produce data relevant to these predictions, because the effects of word length and phonemic similarity were examined in different experiments using different scoring criteria (recall of sequences vs. recall of items). Indeed, it is entirely possible that the discrepancies between the patterns of findings that they obtained with regard to the effects of articulatory suppression originated in other features of their experimental design, materials, or procedure. The following experiment examined these issues by manipulating the three variables of word length, phonemic similarity, and articulatory suppression in an orthogonal manner, using presentation conditions that were broadly similar to those of Baddeley et al. (1984) within a single design (and obviously, therefore, using consistent scoring criteria throughout).

\section{Method}

Subjects. The main study involved 24 Italian university students (12 males and 12 females) with a mean age of 24 years. Another 8 students participated in a further study carried out in order to check on properties of the stimulus materials employed.

Materials. Word length was manipulated by comparing twosyllable and four-syllable Italian words. Phonemic similarity was defined in terms of the occurrence of the letters "or" in the first syllable of two-syllable words and by the occurrence of the letters "nera" in the second and third syllables of four-syllable words. The six phonemically similar, two-syllable words were: porte (doors), corvi (crows), morsa (vice), borgo (burgh), forni (ovens), and lordo (gross). The six phonemically dissimilar, two-syllable 
words were: astri (stars), pozzo (well), danza (dance), penne (pens), vespe (wasps), and giallo (yellow). The six phonemically similar four-syllable words were: minerale (mineral), generato (generated), onerate (encumbered), funerali (funerals), cinerama (cinerama), and venerare (to worship). The six phonemically dissimilar, foursyllable words were: elefante (elephant), navigare (sailing) preferenza (preference), sigaretta (cigarette), demolito (demolished), and lampadina (light bulb). Twelve sequences of four items were derived from each of the four sets of words by the repeated sampling of four items at random without replacement, while two additional sequences from each set of words were used for practice.

Procedure. The sequences of words were recorded at a rate of $1.5 \mathrm{sec} /$ item, with a verbal warning signal $3 \mathrm{sec}$ before the first item and a nonverbal recall cue $2 \mathrm{sec}$ after the last item in each sequence. The subjects were tested individually and were given standard serial-recall instructions. An interval of $20 \mathrm{sec}$ was allowed for the recall of each sequence of items, which were to be written in the order of presentation on a prepared response sheet. ${ }^{2}$ The subjects were presented with the 8 practice sequences and then with the 48 experimental sequences, blocked according to conditions. Twelve different orders of administration of the four conditions were employed across the 12 subjects in each group. Six male subjects and 6 female subjects listened to the sequences in silence; the remainder quietly repeated "uno, due, tre" (i.e., "one, two, three") once every second throughout the presentation and recall of each sequence.

Eight further subjects were tested on their reading and articulation times for the four sets of stimulus material. In the reading test, they were asked to read aloud as quickly as possible the 12 sequences in each set, typed in two columns on a single sheet of paper. In the articulation test, they recited aloud 4 different sequences of three words from each set a total of 10 times. The sequences were randomized and preceded by a practice trial for each condition, four different orders of presentation of the four sets of words were used across different subjects, and the order of administration of the two tasks was counterbalanced across different subjects.

\section{Results}

The data analysis reported here is based upon the subjects' recall of entire sequences, and it is therefore comparable to that of Experiment 2 of Baddeley et al. (1984). Nevertheless, a similar pattern of results was obtained when the response protocols were scored in terms of the subjects' recall of individual items (as in Experiment 4 of Baddeley et al., 1984).

Table 1 shows the mean percentage of sequences correctly recalled in each of the four conditions. An analysis of variance was carried out upon the number of sequences recalled by each subject in each condition, using the between-subjects factor of articulatory suppression and the within-subjects factors of phonemic similarity and word length. The main effects of articulatory suppression $\left[F(1,22)=17.62, M S_{\mathrm{e}}=14.95, p<.001\right]$, phonemic

Table 1

Mean Percentage of Lists Correctly Recalled in Immediate Serial Recall as a Function of Articulatory Suppression, Phonological Similarity, and Word Length in Experiment 1

\begin{tabular}{lccccc}
\hline & \multicolumn{2}{c}{ Distinct } & & \multicolumn{2}{c}{ Similar } \\
\cline { 2 - 3 } \cline { 5 - 6 } & Short & Long & & Short & Long \\
\hline Silent & 86.2 & 73.7 & & 63.2 & 31.2 \\
Suppressed & 52.0 & 49.4 & & 25.0 & 17.5 \\
\hline
\end{tabular}

Table 2

Mean Reading Rate and Articulation Rate (Words/Sec) as a Function of Phonological Similarity and Word Length in Experiment 1

\begin{tabular}{llllll}
\hline & \multicolumn{2}{c}{ Distinct } & & \multicolumn{2}{c}{ Similar } \\
\cline { 2 - 3 } & Short & Long & & Short & Long \\
\hline Reading & 2.26 & 1.85 & & 1.87 & 1.61 \\
Articulation & 2.34 & 1.71 & & 1.89 & 1.39 \\
\hline
\end{tabular}

similarity $\left[F(1,22)=121.10, M S_{\mathrm{e}}=2.76, p<.001\right]$, and word length $\left[F(1,22)=35.41, M S_{\mathrm{e}}=1.84, p<.001\right]$ were all highly significant in the anticipated directions. The two-way interactions between the effects of articulatory suppression and word length $[F(1,22)=14.40$, $\left.M S_{\mathrm{e}}=1.84, p<.001\right]$ and between the effects of phonemic similarity and word length $\left[F(1,22)=6.30, M S_{c}=\right.$ $2.03, p<.02]$ were both statistically significant, but were qualified by the higher order interaction involving all three factors, which approached statistical significance $\left[F(1,22)=2.98, M S_{\mathrm{e}}=2.03, p<.10\right]$.

A posteriori tests were therefore carried out to examine separately the two groups of subjects engaged in silent learning and in articulatory suppression. For those subjects engaged in silent learning, the main effects of phonemic similarity $\left[F(1,22)=66.79, M S_{\mathrm{e}}=2.76\right.$, $p<.001]$ and word length $\left[F(1,22)=46.48, M S_{\mathrm{e}}=\right.$ $1.84, p<.001]$ were both significant, as was the interaction between them $\left[F(1,22)=8.06, M S_{e}=2.02\right.$, $p<.01]$. For those subjects engaged in articulatory suppression, the main effect of phonemic similarity was highly significant $\left[F(1,22)=54.61, M S_{\mathrm{c}}=2.76\right.$, $p<.001]$, but the main effect of word length was not $\left[F(1,22)=2.55, M S_{\mathrm{e}}=1.84, p>.10\right]$, and there was no sign of any interaction $(F<1)$.

Table 2 shows the mean reading and articulation rates obtained on the four types of sequence by the 8 additional subjects. The results from each task were submitted to an analysis of variance that involved the within-subjects factors of phonemic similarity and word length. Phonemic similarity affected reading rate $\left[F(1,7)=50.97, M S_{\mathrm{e}}=\right.$ $0.02, p<.001]$ and articulation rate $[F(1,7)=29.66$, $\left.M S_{\mathrm{e}}=0.04, p<.001\right]$; and word length affected reading rate $\left[F(1,7)=28.48, M S_{\mathrm{e}}=0.03, p<.001\right]$ and articulation rate $\left[F(1,7)=18.22, M S_{\mathrm{e}}=0.14\right.$, $p<.005]$. However, in neither task was there a significant interaction $(p>.10$, in both cases).

\section{Discussion}

The results of this experiment show that under conditions of auditory presentation, articulatory suppression during both presentation and recall abolishes the word length effect in immediate serial recall, but does not diminish the effect of phonemic similarity. This confirms the findings of Baddeley et al. (1984), albeit within a single experimental investigation. Since the effects of phonemic similarity persist when those of word length have been abolished, one may conclude that the form of storage responsible for the former effects must be functionally 
independent from the processes that are manifested in the effect of word length. Indeed, the capacity of phonological storage seems to be a constant number of words, regardless of the number of phonemes or syllables that they contain, which suggests that the functional units of phonological storage are the discrete words rather than their constituent phonemes or syllables. The notion that short-term memory might involve a unitized form of coding in just this sense has been acknowledged since the early work of Miller (1956). Nevertheless, it is clear that the form of representation is phonological rather than lexical, since the degree of disruption caused by unattended speech (see below) is dependent upon its phonemic properties and not upon its semantic content (Salamé \& Baddeley, 1982). In particular, the effect is obtained even if the unattended speech is in an unfamiliar foreign language (Colle \& Welsh, 1976; Jones, Miles, \& Page, 1990; Morris, Jones, \& Quayle, 1989; Salamé \& Baddeley, 1983, 1986, 1989).

The interrelationship obtained between the effect of word length and the effect of phonemic similarity under conditions of silent learning in this experiment is somewhat puzzling: the effect of word length was more pronounced in the case of phonemically similar sequences of items, and the effect of phonemic similarity was more pronounced in the case of sequences of long words. This finding differs from both of the patterns of results envisaged earlier (either no interaction or a reduced word length effect in the case of phonemically similar sequences). A plausible explanation is that the subjects' absolute level of performance on the phonemically dissimilar, two-syllable words was simply constrained by a ceiling effect; Experiment 2, reported below, was carried out in order to assess this idea directly. However, we also looked at some possible artifacts that might explain the pattern of results obtained in the present experiment.

One possibility, for instance, is that the sequences of two-syllable and four-syllable words had not been adequately matched in terms of their phonemic similarity (cf. Cowan et al., 1992). This idea can be dismissed, because under articulatory suppression, equivalent levels of performance were obtained on the two-syllable and foursyllable words in both the distinct condition $(52.0 \%$ vs. $49.4 \%)$ and the similar condition $(25.0 \%$ vs. $17.5 \%)$, in spite of the clear effect of phonemic similarity. The converse possibility is that the phonemically similar and dissimilar words had not been adequately matched in terms of their articulatory duration, and the results of the additional study bear on this point. In previous research using English materials and subjects, the effect of phonemic similarity upon pronunciation time has been rather inconsistent, even between experiments using the same stimulus materials (e.g., Hulme \& Tordoff, 1989; Schweickert, Guentert, \& Hersberger, 1990). However, the results presented in Table 2 do confirm that in the present study the phonemically similar words took somewhat longer to articulate. Consequently, any differences in phonemic confusability were confounded with differences in articulatory duration. Nevertheless, this was equally true of the twosyllable and four-syllable words, and so it follows that the interaction between the effects of word length and phonemic similarity could not be explained in terms of a specific difference in articulatory duration between the similar and the dissimilar four-syllable words.

\section{EXPERIMENT 2}

In order to evaluate the suggestion that in the previous experiment the absolute level of recall performance on the phonemically dissimilar, two-syllable words was simply constrained by a ceiling effect, a second experiment was carried out. This study examined the relationship between the effect of phonemic similarity and the effect of word length under conditions of silent learning when the task had been made more difficult by the simple expedient of extending the sequences of words to be learned.

\section{Method}

This experiment was an exact replication of Experiment 1 except in two respects. First, each of the sequences of items contained five words obtained by random sampling from one of the four original sets of words. Second, all of the 16 Italian university students who served as subjects engaged in silent learning throughout the experiment.

\section{Results and Discussion}

The data analysis was once again based upon the subjects' recall of entire sequences. The mean percentage of sequences correctly recalled in each condition was as follows: phonemically similar, two-syllable words, 20.3; phonemically dissimilar, two-syllable words, 74.5 ; phonemically similar, four-syllable words, 6.8 ; phonemically dissimilar, four-syllable words, 59.9. An analysis of variance produced a highly significant effect of phonemic similarity $\left[F(1,15)=214.17, M S_{\mathrm{e}}=3.10, p<.001\right]$, a highly significant effect of word length $[F(1,15)=34.34$, $M S_{\mathrm{e}}=1.33, p<.001$ ], but no sign of any interaction $(F<1)$. These results confirm that the articulatory duration and the phonemic confusability of items to be remembered exert additive and independent effects upon performance in immediate serial recall, and hence that they reflect distinct components of the working-memory system. However, taken together with the findings of Experiment 1 , these results also emphasize the variety of procedural considerations that need to be taken into account in order to achieve a correct interpretation of the findings of experimental research on working memory.

\section{EXPERIMENT 3}

The results of Experiment 1 indicate that phonemic similarity is not a pure operational indicator of the use of phonological storage. In the case of Italian words (and possibly also in the case of English words), it is associated with slower articulation rates (even when word length in terms of the number of syllables is controlled), and it is thus also, to some extent, an indicator of the articulatory 
control process. Given this inherent confounding between the phonemic similarity of the words to be remembered and their articulatory duration, a second experiment was performed that used an operational indicator of the use of phonological storage which could be manipulated independently of the properties of the stimulus materials that had to be remembered.

Colle and Welsh (1976) demonstrated that the immediate serial recall of visually presented items was impaired if the subjects were exposed to irrelevant speech sounds that they were instructed to ignore. Salamé and Baddeley (1982) found that the magnitude of this impairment was influenced by the degree of phonemic similarity between the unattended speech and the material to be remembered, which suggested that the unattended speech had occupied space within a phonological store. However, long words were no more disruptive as irrelevant items than were short words, which supports the assertion made previously that the capacity of the phonological store is related to the number of encoded items but not to their length. Recent work has indicated that no disruption is produced by a single speech sound that is repeated either continuously or intermittently or by the repeated presentation of a single syllable (Jones, Madden, \& Miles, 1992); conversely, an effect of roughly the same magnitude as that produced by naturally occurring speech is produced by a continuous stream of vowel sounds and even by continuous random pitch glides if these are interrupted by short periods of silence (Jones, Macken, \& Murray, in press). This would imply that the phonological store may be disrupted by a changing stream of irrelevant acoustic stimuli that are segmented either physically (in the case of nonspeech sounds) or categorically (in the case of speech sounds).

It has also been shown that unattended speech impairs performance in the case of sequences of phonemically distinct items, but that it has no effect on performance in the case of sequences of phonemically confusable items (Colle \& Welsh, 1976; Salamé \& Baddeley, 1986). This interaction confirms that the effects of phonemic similarity and of unattended speech do not reflect distinct components of the articulatory loop, but instead constitute alternative operational indicators of one single hypothetical construct (namely, the phonological store). It is, in contrast, assumed that the phonological store is functionally distinct from the articulatory control process, and hence that any operational indicators of this latter construct should be independent of the effect of unattended speech. One such operational indicator is the effect of articulatory suppression, but this can be expected to depend on the presentation modality of the items to be remembered. Miles, Jones, and Madden (1991) found that with visual presentation, the effect of unattended speech was abolished by articulatory suppression during the presentation phase alone. This is consistent with the general theoretical notion that articulatory rehearsal is necessary to encode visual stimuli in a phonological form. With auditory presentation to one ear, however, Hanley and Broadbent (1987) showed that articulatory suppression did not reduce the effect of unattended speech simultaneously presented to the other ear unless the memory task was made so demanding as to discourage the subjects from using a phonological code at all.

It is conventional in research of this sort to present the unattended speech at moderately high sound levels, even though the magnitude of the disruption does not appear to depend upon the acoustic intensity of the irrelevant material, provided that the latter is clearly audible (Colle, 1980; Salamé \& Baddeley, 1983, 1987). This would obviously preclude the simultaneous auditory presentation at normal sound levels of the material that was to be remembered. Hanley and Broadbent (1987) attempted to avoid this problem by presenting the items to be remembered and the unattended speech to different ears. However, this turns their monaural control task (in which the projections to both cerebral hemispheres are activated) into a dichotic listening task (in which the contralateral projections suppress the ipsilateral projections). Hanley and Broadbent did acknowledge the additional problem that, under conditions of auditory presentation, feedback from articulatory suppression might tend to mask the material that was to be remembered. An alternative operational indicator of the articulatory control process is the word length effect, and the theoretical distinction between this control process and the phonological store implies that the effects of word length and of unattended speech in immediate serial recall should be additive and independent of one another, regardless of the modality of presentation. The following experiment, therefore, investigated the effects of word length and of unattended speech upon the immediate serial recall of visually presented sequences of words, using presentation conditions that were broadly similar to those employed by Baddeley et al. (1975) and by Salamé and Baddeley $(1982,1987)$.

\section{Method}

Subjects. The subjects were 24 English students ( 8 males and 16 females) who carried out this experiment as part of a first-year course in research methods

Materials. The stimulus items were taken from Baddeley et al. (1975, Experiment 3). They consisted of two sets of seven words, matched in terms of the numbers of letters, phonemes, and syllables that they contained, where one set (coerce, cyclone, friday, harpoon, humane, nitrate, zygote) tended to have a longer duration when spoken normally than the second set (bishop, ember, pectin, pewter, phallic, wicket, wiggle). Ten different random orderings were generated from each set, and these were combined at random in two blocks each of 10 sequences, such that each block contained 5 sequences of short words and 5 sequences of long words. A pool of 400 high-frequency words provided the irrelevant stimuli.

Procedure. The sequences were presented for immediate serial recall by means of a microcomputer linked to a 24 -in. monochrome video monitor. This displayed the individual words in uppercase characters, roughly $12 \times 10 \mathrm{~mm}$; these were viewed by groups of 6 subjects at a distance of roughly $3 \mathrm{~m}$. The sequences were presented at a rate of 2 sec/item; each sequence was preceded by auditory and visual warning signals and followed by a visual recall cue. The subjects were allowed 40 sec to recall each sequence on a prepared response sheet, at the top of which were printed the two 
sets of seven stimuli that were used in this experiment (following the procedure of Baddeley, 1968). During the presentation and recall of one block of 10 sequences, the subjects were exposed to ambient noise at 35-40 $\mathrm{dB}(\mathrm{A})$ alone. During the presentation and recall of the other block of 10 sequences, the subjects were exposed to irrelevant speech (which they were specifically instructed to ignore) consisting of unrelated words recorded in advance in a male voice at a rate of $1 \mathrm{item} / \mathrm{sec}$ and presented by loudspeaker at $70-80 \mathrm{~dB}(\mathrm{~A})$. The presentation of irrelevant stimuli was not specifically synchronized with that of the items to be remembered, but this does not appear to be an important factor determining the effects of unattended speech (Salamé \& Baddeley, 1982). Two groups of 6 subjects learned the first block of sequences in silence and the second block exposed to unattended speech; for the remaining groups, the order of these two conditions was reversed.

\section{Results and Discussion}

To ensure comparability with the relevant experiments described by Baddeley et al. (1975) and by Salamé and Baddeley $(1982,1987)$, the data analysis reported here was based on subjects' recall of individual items. In the case of the sequences learned in silence, the mean percentage of items correctly recalled was 75.5 for the short words and 65.2 for the long words; in the case of the sequences learned with unattended speech, the corresponding figures were 62.4 and 54.9 , respectively. An analysis of variance was carried out using the betweensubjects factor of order of conditions and the withinsubjects factors of blocks and word length. The effect of unattended speech was identified as the interaction between the effect of blocks and the effect of order of conditions.

This analysis produced a highly significant main effect of blocks $\left[F(1,22)=11.09, M S_{\mathrm{e}}=12.21, p<.005\right]$. Performance on the second block was better than on the first block, representing a significant practice effect, but this effect did not qualify any of the comparisons of theoretical interest ( $p>.30$, in every case). There was also a highly significant effect of word length $[F(1,22)=$ $13.53, M S_{\mathrm{e}}=14.66, p<.001 \mathrm{~J}$ and a highly significant effect of unattended speech $\left[F(1,22)=30.80, M S_{\mathrm{e}}=\right.$ $12.21, p<.001]$, but there was no sign of any interaction between these two effects $(F<1)$. The latter observation confirms the original hypothesis that word length and unattended speech exert additive and independent effects upon performance in immediate serial recall. It is in notable contrast to the consistent finding mentioned earlier of an interactive relationship between the effects of phonemic similarity and unattended speech, such that unattended speech disrupts the retention of phonemically distinct sequences but has no effect on that of phonemically confusable ones (Colle \& Welsh, 1976; Salamé \& Baddeley, 1986).

\section{EXPERIMENT 4}

The results of Experiments 1, 2, and 3 tend to confirm the position of Baddeley et al. (1984) that the effect of word length reflects the contribution of the articulatory control process, whereas the effects of phonemic simi- larity and of unattended speech result from the use of storage in some abstract phonological code. The link between these two components of the articulatory loop subsystem is that the hypothetical short-term phonological trace is assumed to be vulnerable to decay unless it is refreshed by means of articulatory rehearsal (see Baddeley, 1986, pp. 92-96; 1990, p. 72).

As Baddeley and Lewis (1984) pointed out, this assumption entails a specific prediction concerning the effects of articulatory suppression under different rates of auditory presentation. (Under conditions of visual presentation, articulatory suppression is assumed to prevent the stimulus material from being encoded in the form of a phonological trace at all.) Using a rapid rate of presentation, the phonological trace is assumed to be maintained long enough to contribute to recall performance even when rehearsal is prevented by means of articulatory suppression, but with a slower rate of presentation, articulatory suppression should prevent the maintenance of the phonological trace, and as a result, the latter will decay before recall is required. In accordance with this view, Baddeley and Lewis found that a rapid rate of presentation $(0.5 \mathrm{sec} /$ item $)$ produced an increased memory span when compared with a slow rate of presentation $(3 \mathrm{sec} / \mathrm{item})$, but only when rehearsal during the presentation of the stimulus material was prevented by means of articulatory suppression.

Nevertheless, this account is open to a much more rigorous empirical evaluation. If articulatory suppression during presentation and recall is combined with a conventional (i.e., relatively fast) rate of presentation, the phonemic similarity effect is preserved, whereas the word length effect is abolished (Baddeley et al., 1984; Experiment 1 , above). This confirms that the phonological trace has been maintained long enough to contribute to recall performance. If, however, articulatory suppression is combined with a slow rate of presentation, then the phonological trace should decay before the beginning of the recall phase, and therefore the phonemic similarity effect should also be abolished. The following experiment tested this prediction by manipulating articulatory suppression and phonemic similarity with both a conventional rate and a slow rate of auditory presentation.

\section{Method}

Subjects. The subjects in this experiment were 24 English students (12 males and 12 females) who volunteered to participate.

Materials. The two sets of stimulus material were taken from Experiment 6 reported by Baddeley (1968) and had been used in previous investigations of the phonemic similarity effect (Richardson, 1984; Richardson et al., 1980). One set contained six phonemically confusable words (cad, can, cap, cat, mad, man), and the other set contained six phonemically distinct words matched for frequency with those in the first set (bar, bun, day, few, rig, sup). Ten random orderings were derived from each set of stimuli, and these were randomly allocated to two blocks so that each block contained five phonemically confusable sequences and five phonemically distinct sequences, randomly ordered.

Two audio recordings of the sequences were then made using presentation rates of $0.5 \mathrm{sec} / \mathrm{item}$ and $5 \mathrm{sec} / \mathrm{item}$, respectively. Each 
sequence was preceded by a warning ("Here is the first/next list") and followed by the prompt ("Recall") at the appropriate interval after the last item to be remembered (i.e., $0.5 \mathrm{sec}$ or $5 \mathrm{sec}$, respectively).

Procedure. The subjects were tested individually and were given standard serial-recall instructions. The sequences were presented through headphones in the same order to all of the subjects. They attempted to recall the items by writing their responses on a prepared sheet, at the top of which were printed the 12 relevant stimuli (following the procedure of Baddeley, 1968). Half of the subjects were presented with the sequences recorded at a fast rate of presentation, and half were presented with the sequences recorded at a slow rate of presentation. Independently of this, 12 of the subjects listened to the first block of sequences in silence and whispered the word "the" repeatedly as fast as was comfortable during the presentation and recall of the second block of sequences; the remaining 12 subjects carried out these two conditions in the reverse order. An interval of $30 \mathrm{sec}$ was allowed for the recall of each sequence, but the subjects were allowed a short break after each sequence if they wished.

\section{Results}

As in the case of previous studies of the phonemic similarity effect (Richardson, 1984; Richardson et al., 1980), the data analysis reported here was based upon the subjects' recall of individual items. Table 3 shows the mean percentage of items correctly recalled in each of the eight conditions in this experiment. It is clear that articulatory suppression abolished the phonemic similarity effect under a slow rate of presentation but not under a fast rate of presentation.

The statistical reliability of these effects was investigated by means of an analysis of variance carried out upon the total number of phonemically similar and phonemically distinct items that were correctly recalled by each subject in each block of sequences. This analysis employed two between-subjects factors (presentation rate and order of conditions) and two within-subjects factors (articulatory suppression and phonemic similarity). Directional tests (equivalent to one-tailed $t$ tests) produced significant main effects of presentation rate $[F(1,20)=31.04$, $\left.M S_{\mathrm{e}}=56.96, p<.001\right]$, phonemic similarity $[F(1,20)=$ $\left.23.33, M S_{\mathrm{e}}=14.79, p<.001\right]$, and articulatory suppression $\left[F(1,20)=33.24, M S_{\mathrm{e}}=8.43, p<.001\right]$. The interaction between the effects of presentation rate and phonemic similarity $\left[F(1,20)=5.96, M S_{\mathrm{e}}=14.79\right.$, $p<.02]$ was statistically significant, and the interaction between the effects of phonemic similarity and articulatory suppression approached significance $[F(1,20)=$ $2.54, M S_{\mathrm{e}}=7.94, p=.06$ ], but the interaction between

Table 3

Mean Percentage Correct in Immediate Serial Recall of Phonemically Distinct and Similar Items Under Silent Learning and Articulatory Suppression and Under Fast and Slow Rates of Presentation in Experiment 4

\begin{tabular}{lccccc}
\hline & \multicolumn{2}{c}{ Silent } & & \multicolumn{2}{c}{ Suppressed } \\
\cline { 2 - 3 } & Distinct & Similar & & Distinct & Similar \\
\hline Fast & 70.0 & 51.1 & 56.9 & 37.8 \\
Slow & 93.6 & 81.1 & 77.8 & 77.8
\end{tabular}

the effects of presentation rate and articulatory suppression did not $(F<1)$. The three-way interaction between the effects of presentation rate, phonemic similarity, and articulatory suppression also approached statistical significance $\left[F(1,20)=2.78, M S_{\mathrm{e}}=7.94, p=.06\right]$; however, this encompasses a number of different possible interactive relationships and is therefore a very conservative test of the theoretical hypothesis under evaluation.

Directional a posteriori tests demonstrated that the interaction between the effects of presentation rate and phonemic similarity was significant under conditions of articulatory suppression $\left[F(1,40)=8.73, M S_{\mathrm{c}}=11.36\right.$, $p<.005$ ], but not under conditions of silent learning $(F<1)$. The interaction between the effects of phonemic similarity and articulatory suppression was significant under a slow rate of presentation $\left[F(1,20)=5.32, M S_{\mathrm{e}}=\right.$ 7.94, $p<.025$ ], but not under a fast rate of presentation $(F<1)$. Further tests showed that the simple main effect of phonemic similarity was significant under conditions of silent learning $\left[F(1,40)=23.41, M S_{e}=11.36\right.$, $p<.001]$ and under $a$ fast rate of presentation $\left[F(1,20)=26.44, M S_{\mathrm{e}}=14.79, p<.001\right]$ but not under a slow rate of presentation and conditions of articulatory suppression $(F<1)$.

\section{Discussion}

Previous research using auditory presentation of sequences of items has demonstrated that articulatory suppression has a modest effect on the absolute level of performance, but has little or no influence upon the magnitude of the phonemic similarity effect (Levy, 1971; Murray, 1968; Peterson \& Johnson, 1971), even when the subjects are required to engage in articulatory suppression during both presentation and recall (Baddeley et al., 1984; Experiment 1, above). These findings were confirmed in the present experiment when a conventional, fairly rapid rate of presentation was used. They suggest that the material to be learned is held in working memory in some phonological form, but that the encoding of spoken material into this phonological store and the retrieval of stimulus items from this phonological store do not depend upon the use of articulatory rehearsal. Nevertheless, under a slow rate of presentation, the phonemic similarity effect was completely abolished by articulatory suppression during both presentation and recall. This is consistent with the notion, formulated earlier on the basis of recent theoretical discussions of the structure and function of working memory, that the maintenance of items within a phonological store depends upon the process of articulatory rehearsal.

In the present experiment, the phonemic similarity effect was still obtained under conditions of silent learning even with a relatively slow rate of presentation, and this entails that the phonological store can be used to maintain information over short time intervals. The magnitude of this phonemic similarity effect was slightly (although not significantly) reduced under the slow rate of presentation. Table 3 indicates that this was in part because the 
absolute level of performance with a slow rate of presentation was approaching a ceiling. According to their own accounts on debriefing, the subjects in the present experiment were able to exploit the longer interstimulus intervals to try to anticipate the items that were still to be presented on the basis of their knowledge of the structure of the word sequences that were to be learned. As a result, their efforts at learning the stimulus material were not totally dependent upon phonological encoding, and this might well have tended to weaken the effect of phonemic similarity upon their recall performance.

In addition, this improvement in performance with a slow presentation rate occurred even when the subjects engaged in articulatory suppression, which is opposite to the findings that were obtained by Baddeley and Lewis (1984). One important difference is that the materials employed by these latter researchers consisted of sequences of digits, and it could thus be argued to have been semantically impoverished; consequently, their recall task would have depended almost exclusively upon the use of a phonological form of encoding that was maintained by means of articulatory rehearsal. In contrast, in the present experiment, the material consisted of sequences of familiar words, and this might have permitted the use of some semantic form of encoding that would not depend upon the use of subvocal rehearsal. The present findings are in fact entirely consistent with the view that one component in the immediate serial recall of sequences of words is a semantically based, long-term store (see Gregg, Freedman, $\&$ Smith, 1989), and that the relative contribution of this store to overall performance is greater under slower rates of presentation. Direct evidence for this view was recently provided by Hulme, Maughan, and Brown (1991), who showed that memory span was greater for words than for nonwords, and that memory span for words in an unfamiliar foreign language was increased by the subjects' learning the translations of those words into their native language. The results shown in Table 3 also indicate that with a slow presentation rate articulatory suppression had little effect upon the recall of phonemically similar sequences of words, and this suggests that subvocal rehearsal made essentially no contribution to performance under those circumstances.

Nevertheless, as Pierre Salamé, one of our referees, pointed out to us, this line of argument suggests an entirely different interpretation of the results of the present experiment. In comparison with the results of Baddeley and Lewis (1984), the improved performance obtained with a slow presentation rate, even with articulatory suppression, indicates that under these circumstances the subjects were able to adopt a more efficient form of coding that did not depend upon the use of articulatory rehearsal. As a consequence, the absence of a significant effect of phonemic similarity upon their performance could be taken to reflect an intentional change in encoding strategy (from a phonological to a nonphonological code), rather than merely the inevitable result of any process of trace decay within the phonological store. Such a view would be consistent, for example, with an analysis of short-term memory phenomena put forward by Nairne (1988), who argued that the effects of phonemic similarity in immediate serial recall could be ascribed to the overwriting of the encoded phonological features of previously presented items by the encoding of subsequent events sharing the same features in terms of their speech-based properties. As a result, these effects can be explained in terms of the choice of specific encoding operations without recourse to the assumption of any decaying phonological trace.

One way to discriminate between these two alternative explanations would be to investigate the effects of articulatory suppression using a conventional presentation rate when a brief delay was interposed between the presentation and the recall of each sequence of words. On the one hand, an obvious prediction from the decay hypothesis is that articulatory suppression during the interposed interval should prevent the maintenance of any phonological trace, and hence the phonemic similarity effect should be abolished. On the other hand, under the encoding strategy hypothesis, the introduction of a delay would not itself entail any change in encoding conditions. Even if this delay were occupied by articulatory suppression, it would not involve the presentation and encoding of interfering material and hence there would be no overwriting of the previously presented items. On this account, therefore, one would expect no reduction in the magnitude of the phonemic similarity effect, provided that the encoding operations continued to be based upon the phonological properties of the material.

\section{EXPERIMENT 5}

In fact, two previous studies have investigated the impact of a delay occupied by irrelevant tasks upon the phonemic similarity effect obtained with sequences of consonants. With these materials, there would seem to be no possibility of subjects' using some alternative semantic code, and so the encoding strategy hypothesis would have to predict no reduction in the magnitude of the phonemic similarity effect. The first study, by Posner and Konick (1966), employed a Brown-Peterson paradigm to investigate the recall of auditorily presented sequences of consonants after delays of $0,5,10$, and $20 \mathrm{sec}$, during which the subjects were occupied with either the addition of digit pairs or their classification as high or low and odd or even. While there was substantial forgetting, especially during the first $5 \mathrm{sec}$, there was no sign of any reduction in the magnitude of the phonemic similarity effect, even after an interval of $20 \mathrm{sec}$. However, because the subjects' responses to the digit pairs were written rather than spoken, it would, in principle, be possible to reconcile these results with the decay hypothesis by assuming that neither of the irrelevant tasks had deployed the resources of the articulatory loop.

Subsequently, Conrad (1967) compared the matrices of confusion errors obtained in the recall of visually presented sequences of consonants after delays of either 2.4 
or $7.2 \mathrm{sec}$, during which the subjects read aloud a series of visually presented digits. With the brief delay, the proportion of errors was $38 \%$, of which $59 \%$ were phonemically similar to the relevant correct response; with the longer delay, the proportion of errors was $62 \%$, but of these only $38 \%$ were phonemically similar to the correct response (see also Conrad, 1972). Conrad (1967) noted that, by chance, $31 \%$ of errors would have been expected to be phonemically similar to the correct response, and he concluded that his results were consistent with the assumption of decay of phonological traces within shortterm memory. He dismissed an account in terms of proactive interference from previously presented sequences of consonants, but a proponent of the encoding strategy hypothesis could well maintain that Conrad's (1967) findings were contaminated by potential overwriting (retroactive interference) from the shadowed digits, especially since the latter were displayed in one continuous sequence with the consonants that had to be remembered (cf. Nairne, 1988).

A recent study by Miles et al. (1991) produced evidence relevant to this problem in experiments where recall was delayed by a 10 -sec interval, during which the subjects were presumed to engage in covert articulatory rehearsal to maintain the contents of the phonological store. Consistent with this idea, performance was consistently impaired by irrelevant speech presented during the "rehearsal" interval alone. However, this unattended speech effect was abolished when the subjects were also required to engage in articulatory suppression during the same interval, which would indicate that the contents of the phonological store are lost within $10 \mathrm{sec}$ if they cannot be refreshed by articulatory rehearsal. Nevertheless, in a review of research evidence obtained in a wide variety of experimental paradigms, Cowan (1984) concluded that the representation of spoken materials within a short-term phonological store might be available for at least $10 \mathrm{sec}$ and possibly for as long as $20 \mathrm{sec}^{3}$ The following experiment was therefore carried out to determine directly whether the phonemic similarity effect in serial recall would be reduced or abolished by a 10-sec delay occupied by articulatory suppression.

\footnotetext{
Method

Subjects. The subjects in this experiment were 24 English students (9 males, 15 females) who volunteered to participate.

Materials. This experiment employed the same stimulus materials as in Experiment 4. Two different audio recordings of the sequences were made using a presentation rate of $0.5 \mathrm{sec} / \mathrm{item}$. In one recording, the cue "Recall" occurred $0.5 \mathrm{sec}$ after the last item to be remembered in each of the sequences, but in the other recording it occurred $10 \mathrm{sec}$ afterward. The two recordings were identical in all other respects.

Procedure. The basic procedure was the same as that of Experiment 4. Half of the subjects were presented with each of the two audio recordings. Independently of this, 12 of the subjects listened to the first block of sequences in silence and whispered the word "hi-ya" repeatedly as fast as was comfortable throughout the presentation, the interposed interval, and the recall of the second block
}

Table 4

Mean Percentage Correct in Serial Recall of Phonemically Distinct and Similar Items Under Silent Learning and Articulatory Suppression With Immediate and Delayed Recall in Experiment 5

\begin{tabular}{lccccc} 
& \multicolumn{2}{c}{ Silent } & & \multicolumn{2}{c}{ Suppressed } \\
\cline { 2 - 3 } & Distinct & Similar & & Distinct & Similar \\
\hline Immediate & 59.4 & 40.6 & & 40.3 & 27.2 \\
Delayed & 79.4 & 50.3 & & 57.8 & 38.1 \\
\hline
\end{tabular}

of sequences; the remaining 12 subjects carried out these two conditions in the reverse order.

\section{Results}

As in Experiment 4, the data analysis was based upon the subjects' recall of individual items. Table 4 shows the mean percentage of items that were correctly recalled in each of the eight conditions in this experiment. It is clear that articulatory suppression had relatively little effect upon the magnitude of the phonemic similarity effect, even when an interval of $10 \mathrm{sec}$ was interposed between presentation and recall. Indeed, the overall performance of the subjects tested with a 10 -sec delay was actually better than that of the subjects who were tested immediately.

As in Experiment 4, the statistical reliability of these effects was investigated by means of an analysis of variance carried out upon the total number of phonemically similar and phonemically distinct items that were correctly recalled by each subject in each block of sequences. This analysis employed two between-subjects factors (recall delay and order of conditions) and two within-subjects factors (articulatory suppression and phonemic similarity). Directional tests (equivalent to one-tailed $t$ tests) produced significant main effects of both phonemic similarity $\left[F(1,20)=55.60, M S_{\mathrm{e}}=15.86, p<.001\right]$ and articulatory suppression $\left[F(1,20)=41.96, M S_{\mathrm{e}}=14.18\right.$, $p<.001]$. The effect of recall delay was also significant $\left[F(1,20)=6.48, M S_{\mathrm{e}}=70.20, p<.02\right]$, but it failed to show an interaction with either the effect of phonemic similarity $\left[F(1,20)=2.44, M S_{e}=15.86\right.$, $p>0.10$ ] or the effect of articulatory suppression $\left[F(1,20)=0.02, M S_{\mathrm{e}}=14.18, p>.80\right]$. Finally, the interaction between the effects of phonemic similarity and articulatory suppression approached significance $\left[F(1,20)=3.54, M S_{\mathrm{e}}=8.90, p<.10\right]$, but there was no sign of any three-way interaction between the effects of phonemic similarity, articulatory suppression, and recall delay $\left[F(1,20)=0.20, M S_{\mathrm{e}}=8.90, p>.60\right]$.

\section{Discussion}

The results of this experiment confirm those of Experiments 1 and 4, as well as those of Baddeley et al. (1984), in showing that articulatory suppression has little or no influence upon the magnitude of the phonemic similarity effect obtained in the immediate serial recall of spoken words presented at a conventional, fairly rapid rate. This 
suggests once again that the encoding of spoken material into a phonological store as well as the retrieval of such material from this store do not depend upon the use of articulatory rehearsal. Nevertheless, the important additional aspect of the present experiment is that essentially the same pattern of results was obtained when the recall of each sequence of words was delayed by an interval of $10 \mathrm{sec}$. In particular, the phonemic similarity effect showed no sign of any reduction when the subjects had been required to engage in articulatory suppression for the duration of that interval. Clearly this is an important finding from a theoretical point of view, and we must add that we have subsequently replicated it in studies using both English and Italian subjects and with intervals of up to $20 \mathrm{sec}$. It directly refutes the position adopted by Baddeley $(1986$, pp. $92-96 ; 1990$, p. 72 ), that the phonological trace is vulnerable to rapid decay unless it can be refreshed by means of a process of articulatory rehearsal. It suggests instead that the effects of phonemic similarity should be attributed to the employment of speechbased encoding operations at the time of presentation and to the overwriting of the encoded features of the previously presented items by subsequent events sharing the same speech-based features (Nairne, 1988).

The present experiment found an increase in the level of performance between the immediate and delayed recall of sequences of words, a result that is on the face of it somewhat counterintuitive. This improvement in performance was not associated with any reduction in the magnitude of the phonemic similarity effect; indeed, the effect was, if anything, somewhat more pronounced if recall was delayed by a 10 -sec interval. Two possible explanations present themselves. The first is that the delay of $10 \mathrm{sec}$ reduced the output interference that is associated with immediate serial recall (cf. Cowan et al., 1992) and enabled the subjects to engage in additional, semantically based encoding operations that supplemented the phonemic codes created during the presentation of each sequence of items. However, the second and more likely explanation of the present findings is that the word "recall" is known to act as a redundant stimulus suffix that impairs the retention of a previously presented sequence (Morton, Crowder, \& Prussin, 1971, Experiment 2; Roediger \& Crowder, 1976). If the items to be remembered are words, this suffix effect is independent of their level of phonemic similarity (Richardson, 1979). The potency of a stimulus suffix is maximal when it occurs in the same regular sequence as the items to be remembered, and is reduced when the presentation of the suffix is delayed (see Frankish \& Turner, 1984; Watkins \& Watkins, 1980). In particular, a delay of $10 \mathrm{sec}$ renders the recall cue ineffective as a stimulus suffix, leading to improved performance especially on the last few items in each sequence (Crowder, 1969). This sort of interpretation was confirmed by a detailed examination of serialposition curves in the present experiment. Nairne (1988) noted that an encoding strategy hypothesis can also handle such stimulus suffix effects without having to assume any decaying trace.

\section{GENERAL DISCUSSION}

The initial findings of the present investigation with regard to the phenomena characteristic of immediate serial recall can be summarized very easily. First, under conditions of auditory presentation, the word length effect is eliminated by articulatory suppression during presentation and recall. Second, however, under conditions of auditory presentation, the phonemic similarity effect is not diminished by articulatory suppression during presentation and recall, provided that the items to be remembered are presented at a conventional (in other words, a fairly rapid) rate. Third, under conditions of auditory presentation, the effect of phonemic similarity is broadly independent of the effect of word length. Fourth, under conditions of visual presentation, the effect of unattended speech is broadly independent of the effect of word length.

Taken together, these findings provide further comprehensive evidence with regard to the different converging operations that characterize the two principal components of the hypothesized articulatory loop subsystem of working memory. The first component is a short-term phonological store that is operationally defined by the effect of phonemic similarity and the effect of unattended speech. It contains discrete stimulus items that are represented in an abstract phonological code, and these are vulnerable to displacement by irrelevant spoken material. The second component is an articulatory control process that is operationally defined by the effects of word length and articulatory suppression. This can serve as a form of covert rehearsal, but its use is prohibited when subjects engage in the concurrent vocalization of irrelevant sounds. With visual presentation, this control process is also required to translate verbal stimuli into a phonological code (Richardson, 1984; but cf. Logie, Cubelli, Della Sala, Alberoni, \& Nichelli, 1989).

However, in addition to these assumptions regarding the architecture of working memory, it has also been hypothesized that the contents of the short-term phonological store are vulnerable to relatively rapid decay unless they can be refreshed by means of articulatory rehearsal. Research on the word length effect led Baddeley (1990, p. 72) to conclude that this process of decay was complete inside a period of $1 \frac{1}{2}-2 \mathrm{sec}$, but within the elaborated model of working memory this estimate relates to the operating capacity of the articulatory control process, and hence says nothing about the decay characteristics of the phonological store. Elsewhere, Baddeley (1986, pp. 93-94) and other investigators (e.g., Cowan et al., 1992) have described results showing forgetting of individual items within the first $2 \mathrm{sec}$ after their presentation. However, such results do not entail that the phonological trace decays completely within this period, and they also confound the effects of decay with those of interpolated activities.

An implication of the trace decay hypothesis is that under conditions of articulatory suppression, the contribution of the phonological store to performance in the immediate serial recall of spoken material should be in- 
versely related to the presentation time (see Baddeley \& Lewis, 1984). Consequently, both the absolute level of performance and the magnitude of the phonemic similarity effect should be reduced by a relatively slow rate of presentation. A more direct implication is that under conditions of articulatory suppression, the contribution of the phonological store should be inversely related to the interval between the presentation and recall of a particular sequence of items. Consequently, both the absolute level of performance and the magnitude of the phonemic similarity effect should be reduced in delayed recall compared with immediate recall. Experiments 4 and 5 failed to confirm these predictions. Performance was found to be significantly better with a slower presentation rate and with a delay of $10 \mathrm{sec}$, even under conditions of articulatory suppression. In addition, the effect of phonemic similarity was abolished by a relatively slow rate of presentation but was not reduced by an interpolated delay of $10 \mathrm{sec}$.

The exact temporal characteristics of the phonemic similarity effect under conditions of articulatory suppression will need to be established in further research. However, it seems to be the case that phonological information can be maintained in working memory for at least $10 \mathrm{sec}$ (and possibly for as long as $20 \mathrm{sec}$ ), even without the support of articulatory rehearsal. This result cannot be readily handled by the decay hypothesis, but it does accord reasonably well with an encoding strategy hypothesis of the sort put forward by Nairne (1988), as do the increases in the absolute level of performance associated with a slower presentation rate or a delay between presentation and recall. Performance in tests of immediate serial recall therefore seems to be a function of the precise encoding operations that are imposed upon the presented sequence, the number of discrete items that can be held in the phonological store, and the rate at which subjects are able to engage in articulatory rehearsal (cf. Baddeley \& Lewis, $1984)$, but is apparently not related to any hypothetical decay process affecting the memory traces of stimulus items held in the phonological store.

\section{REFERENCES}

BADDELEY, A. D. (1968). How does acoustic similarity influence shortterm memory? Quarterly Journal of Experimental Psychology, 20, 249-264.

BADdeley, A. D. (1976). The psychology of memory. New York: Basic Books.

Baddeley, A. D. (1979). Working memory and reading. In P. A. Kolers, M. E. Wrolstad, \& H. Bouma (Eds.), Processing of visible language (Vol. 1, pp. 355-370). New York: Plenum.

BADDELEY, A. D. (1986). Working memory. Oxford: Oxford University Press.

BADDELEY, A. D. (1990). Human memory: Theory and practice. Hove: Erlbaum.

Baddeley, A. D., \& Hitch, G. J. (1974). Working memory. In G. H. Bower (Ed.), The psychology of learning and motivation: Advances in research and theory (Vol. 8, pp. 47-89). New York: Academic Press.
BADDELEY, A., \& LEWIS, V. (1984). When does rapid presentation enhance digit span? Bulletin of the Psychonomic Society, 22, 403-405.

Baddeley, A. D., Lewis, V. J., \& VAlLaR, G. (1984). Exploring the articulatory loop. Quarterly Joumal of Experimental Psychology, 36A, 233-252.

Baddeley, A. D., Thomson, N., \& Buchanan, M. (1975). Word length and the structure of short-term memory. Journal of Verbal Learning \& Verbal Behavior, 14, 575-589.

Baddeley, A. D., \& Wilson, B. (1985). Phonological coding and shorterm memory in patients without speech. Journal of Memory \& Language, 24, 490-502.

Bishop, D. V. M., \& RoBson, J. (1989). Unimpaired short-term memory and rhyme judgement in congenitally speechless individuals: Implications for the notion of "articulatory coding." Quarterly Journal of Experimental Psychology, 41A, 123-140.

COLLE, H. A. (1980). Auditory encoding in visual short-term recall: Effects of noise intensity and spatial location. Journal of Verbal Learning \& Verbal Behavior, 19, 722-735.

COLLE, H. A., \&ELSH, A. (1976). Acoustic masking in primary memory. Journal of Verbal Learning \& Verbal Behavior, 15, 17-32.

CONRAD, R. (1967). Interference or decay over short retention intervals? Journal of Verbal Learning \& Verbal Behavior, 6, 49-54

ConRad, R. (1972). Speech and reading. In J. F. Kavanagh \& I. G. Mattingly (Eds.), Language by ear and by eye: The relationships between speech and reading (pp. 205-240). Cambridge, MA: MIT Press.

Cowan, N. (1984). On short and long auditory stores. Psychological Bulletin, 96, 341-370.

Cowan, N., Day, L., Saults, J. S., Keller, T. A., Johnson, T., \& FLores, L. (1992). The role of verbal output time in the effects of word length on immediate memory. Journal of Memory \& Language, 31, 1-17

Crowder, R. G. (1969). Improved recall for digits with delayed recall cues. Journal of Experimental Psychology, 82, 258-262.

Frankish, C., \&uRner, J. (1984). Delayed suffix effect at very short delays. Journal of Experimental Psychology: Leaming, Memory, \& Cognition, 10, 767-777.

Garner, W. R., Hake, H. W., ERiksen, C. W. (1956). Operationism and the concept of perception. Psychological Review, 63, 149-159.

GregG, V. H., Freedman, C. M., Smith, D. K. (1989). Word frequency, articulatory suppression and memory span. British Joumal of Psychology, 80, 363-374.

Hanley, J. R., Broadbent, C. (1987). The effect of unattended speech on serial recall following auditory presentation. British Journal of Psychology, 78, 287-297.

HiтcH, G. J. (1980). Developing the concept of working memory. In G. Claxton (Ed.), Cognitive psychology: New directions (pp. 154-196). London: Routledge \& Kegan Paul.

Hulme, C., Maughan, S., Brown, G. D. A. (1991). Memory for familiar and unfamiliar words: Evidence for a long-term memory contribution to short-term memory span. Journal of Memory \& Language, 30, 685-701.

HulmE, C., \& TORDOFF, V. (1989). Working memory development: The effects of speech rate, word length, and acoustic similarity on serial recall. Joumal of Experimental Child Psychology, 47, 72-87.

Jones, D. M., MACKen, W. J., Murray, A. C. (in press). Disruption of visual short-term memory by changing-state auditory stimuli: The role of segmentation. Memory \& Cognition.

Jones, D. M., Madden, C., \& Miles, C. (1992). Privileged access by irrelevant speech to short-term memory: The role of changing state. Quarterly Journal of Experimental Psychology, 44A, 645-669.

JoNES, D. M., MiLES, C., \& PAGE, J. (1990). Disruption of proofreading by irrelevant speech: Effects of attention, arousal, or memory? Applied Cognitive Psychology, 4, 89-108.

LEVY, B. A. (1971). Role of articulation in auditory and visual shortterm memory. Journal of Verbal Learning \& Verbal Behavior, 10, 123-132.

logie, R., Cubelli, R., Della Sala, S., Alberoni, M., \& NichelLI, P. (1989). Anarthria and verbal short-term memory. In 
J. R. Crawford \& D. M. Parker (Eds.), Developments in clinical and experimental neuropsychology (pp. 203-211). New York: Plenum.

Miles, C., Jones, D. M., \& Madden, C. A. (1991). Locus of the irrelevant speech effect in short-term memory. Journal of Experimental Psychology: Learning, Memory, \& Cognition, 17, 578-584

MiLleR, G. A. (1956). The magical number seven, plus or minus two: Some limits on our capacity for processing information. Psychological Review, 63, 81-97.

Morris, N., Jones, D. M., \& Quayle, A. J. (1989). In E. Megaw (Ed.), Contemporary ergonomics (pp. 494-499). London: Taylor \& Francis.

Morris, R. G. (1984). Dementia and the functioning of the articulatory loop system. Cognitive Neuropsychology, 1, 143-157.

Morton, J., Crowder, R. G., \& Prussin, H. A. (1971). Experiments with the stimulus suffix effect. Journal of Experimental Psychology Monographs, 91, 169-190

MURRAY, D. J. (1967). The role of speech responses in short-term memory. Canadian Journal of Psychology, 21, 263-276.

MuRRaY, D. J. (1968). Articulation and acoustic confusability in shortterm memory. Journal of Experimental Psychology, 78, 679-684.

NAIRNE, J. S. (1988). A framework for interpreting recency effects in immediate serial recall. Memory \& Cognition, 16, 343-352.

Peterson, L. R., \& Johnson, S. F. (1971). Some effects of minimizing articulation on short-term retention. Journal of Verbal Learning \& Verbal Behavior, 10, 346-354.

Posner, M. I., \& Konick, A. F. (1966). On the role of interference in short-term retention. Journal of Experimental Psychology, 72, 221-231.

Richardson, J. T. E. (1979). Precategorical acoustic storage and postcategorical lexical storage. Cognitive Psychology, 11, 265-286.

RicharDSON, J. T. E. (1984). Developing the theory of working memory. Memory \& Cognition, 12, 71-83.

Richardson, J. T. E., Greaves, D. E., Smith, M. M. C. (1980). Does articulatory suppression eliminate the phonemic similarity effect in short-term recall? Bulletin of the Psychonomic Society, 16, 417-420.

Roediger, H. L., \& Crowder, R. G. (1976). Recall instructions and the suffix effect. American Journal of Psychology, 89, 115-125.

Salamé, P., \& Baddeley, A. (1982). Disruption of short-term memory by unattended speech: Implications for the structure of working memory. Journal of Verbal Learning \& Verbal Behavior, 21, 150-164.

SAlame, P., BADDELEY, A. (1983). Differential effects of noise and speech on short-term memory. In G. Rossi (Ed.), Proceedings of the 4th International Congress on Noise as a Public Health Problem (Vol. 2, pp. 751-758). Milan: Centro Ricerche e Studi Amplifon.

Salame, P., \& Baddeley, A. (1986). Phonological factors in STM: Similarity and the unattended speech effect. Bulletin of the Psychonomic Society, 24, 263-265.

Salame, P., \& Baddeley, A. (1987). Noise, unattended speech and short-term memory. Ergonomics, 30, 1185-1194.

Salamé, P., \& Baddeley, A. (1989). Effects of background music on phonological short-term memory. Quarterly Journal of Experimental Psychology, 41A, 107-122.

SChweickert, R., Guentert, L., \& Hersberger, L. (1990). Phonological similarity, pronunciation rate, and memory span. Psychological Science, 1, 74-77

VAllar, G., \& BADDEley, A. D. (1984). Fractionation of working memory: Neuropsychological evidence for a phonological short-term store. Journal of Verbal Learning \& Verbal Behavior, 23, 151-161.

VAllar, G., CAPPA, S. F. (1987). Articulation and verbal short-term memory: Evidence from anarthria. Cognitive Neuropsychology, 4, 55-77.

Watkins, O. C., \& Watkins, M. J. (1980). The modality effect and echoic persistence. Joumal of Experimental Psychology: General, 109, 251-278.

\section{NOTES}

1. Recent research has demonstrated effects of both word length and phonemic similarity in at least some patients with acquired or congenital anarthria (Baddeley \& Wilson, 1985; Bishop \& Robson, 1989; Vallar \& Cappa, 1987). This implies that covert rehearsal does not depend upon the use of subvocal articulatory gestures, and Baddeley $(1990$, p. 87) has therefore suggested that this subsystem of working memory is better described as a "phonological loop" than as an "articulatory loop."

2. Baddeley et al. (1984) pointed out that long and short words may differ in terms of the time taken to write each item down. In their own study, therefore, they either allowed the subjects to write long words in an abbreviated form (Experiment 4) or encouraged them to abbreviate their responses to the first three or four letters in each word (Experiment 5). To examine directly the possibility that the time taken to write down the items was a significant confounded factor determining recall performance, a preliminary experiment was carried out with 24 subjects, using only the sequences of phonemically dissimilar, four-syllable items. Half of these subjects engaged in silent learning, whereas the remainder engaged in articulatory suppression. Independent of this manipulation, half of the subjects attempted to recall the complete words, whereas the remaining subjects were tested by partial recall in which they had merely to write down only the first two syllables of each word. There was no significant advantage for the subjects who were asked for partial recall, whether they had been engaged in silent learning $(t<1)$ or in articulatory suppression $[t(11)=1.57, p>.05]$. Thus, any differences in the time taken to write long and short words do not appear to influence the results obtained using an unpaced, whole-word written recall procedure. In contrast, Cowan et al. (1992) argued that one determinant of memory performance in earlier studies using oral recall (e.g., Baddeley et al., 1975) was the time taken to articulate particular words during the recall phase itself. Nevertheless, they acknowledged that any explanation of the word length effect in terms of output factors could not explain why the effect disappears under conditions of articulatory suppression (nor, indeed, can it handle effects of word length obtained with written recall if the number of letters in each stimulus is controlled, as in Experiment 3 of the present paper).

3. Such a conclusion would not be inconsistent with the findings of Experiment 4, because with a presentation rate of $5 \mathrm{sec} / \mathrm{item}$ all of the items except the very last in each sequence would have been subject to a presentation-recall interval of $10 \mathrm{sec}$ or longer. It is true that the final item in each sequence was presented only $5 \mathrm{sec}$ before the recall cue and yet there was still no sign of any phonemic similarity effect at this serial position under conditions of articulatory suppression (the recall performance being $76.7 \%$ correct in the case of both phonemically distinct and phonemically similar sequences). Nevertheless, because the subjects were required to recall the items in the order of their presentation, the process of recalling the earlier items meant that the effective delay in the case of the last item in each sequence was typically much longer than $5 \mathrm{sec}$ (cf. Cowan et al., 1992).

(Manuscript received June 22, 1990; revision accepted for publication May 15, 1992.) 